\title{
O silêncio sobre a Educação Ambiental nos cursos de Pedagogia das Universidades Federais do Brasil
}

\author{
Gislânya Santos Teixeira*a, Hellen Lourdes Ramos Marques ${ }^{b}$, Rosemeire da Silva Dantas \\ Oliveirac, Whendel Cezar Silva de Couto ${ }^{d}$, Elton Casado Firemane \\ a Universidade Federal de Alagoas, Alagoas, Maceió, 57063-830, Brasil. *gislanya.teixeira@gmail.com \\ b Grupo Formação de professores e Ensino de Ciências, Universidade Federal de Alagoas, Alagoas, Maceió, 57072-900, Brasil. \\ c Programa de Pós-Graduação em Educação, Universidade Federal de Alagoas, Alagoas, Maceió, 57072-900, Brasil. \\ d Núcleo de Ensino e Pesquisa Arqueológica, Universidade Federal de Alagoas, Alagoas, Maceió, 57073-292, Brasil. \\ e Programa de Pós-Graduação em Educação e Programa de Pós-Graduação em Ensino de Ciências e Matemática, Universidade \\ Federal de Alagoas, Alagoas, Maceió, 57072-900, Brasil.
}

Recebido: 28 setembro 2018 / Aceito: 1 dezembro 2019 / Publicado online: 27 maio 2019

\begin{abstract}
Resumo
Este artigo analisou e discutiu a oferta da Educação Ambiental em cursos de pedagogia de Universidade federais do Brasil e as implicações para a formação do pedagogo em Educação Ambiental. Esta é uma pesquisa de natureza quali e quantitativa. Foram selecionados 27 cursos de pedagogia, um em cada capital do Brasil. Para análises, foram coletados dados nas grades curriculares, ementas das disciplinas para verificar a presença da Educação Ambiental em disciplinas que descrevesse a sua inserção. Foi observado que a Educação Ambiental não é priorizada pelos referidos cursos, $30 \%$ dos cursos pesquisados não a inseriam como disciplina, o que pode gerar uma problemática na formação do educador ambiental e, consequentemente na sociedade. Com essa problemática na formação, sua atuação em sala de aula poderá ser comprometida, não favorecendo aos educandos o ensino do saber da Educação Ambiental amplo e crítico e que também os tornem sujeitos capazes mediadores dessa consciência, na sociedade. Investir nessa formação é o caminho para que o docente tenha competências e habilidades para esse saber ainda em sua formação de graduação.
\end{abstract}

Palavras-chave: Capacitação docente, currículo acadêmico, graduação, meio ambiente.

\section{The silence about Environmental Education in the Pedagogy Courses from the Federal Universities of Brazil}

\begin{abstract}
This article analyzed and discussed the offer of Environmental Education in courses of pedagogy of Federal University of Brazil and the implications for the education of the pedagogue in Environmental Education. This is a qualitative and quantitative research. Twenty-seven pedagogy courses were selected, one in each Brazilian capital. For analysis, data were collected in curricula, subjects' menus to verify the presence of Environmental Education in disciplines describing their insertion. It was observed that Environmental Education is not prioritized by these courses, $30 \%$ of the courses surveyed did not include it as a discipline, which can generate a problem in the formation of the environmental educator and, consequently, in society. With this problematic in the training, its performance in the classroom could be compromised, not favoring to the students the teaching of the knowledge of the Environmental Education ample and critical and that also make them capable subjects mediators of that consciousness, in the society. Investing in this training is the way for the teacher to have the skills and abilities to know this still in their undergraduate education.
\end{abstract}

Keywords: Teacher training, academic curriculum, graduation, environment.

\section{Introdução}

As questões ambientais precisam estar melhor inserida no âmbito educacional brasileiro. Elas são vistas diariamente, mas de forma vaga sem a adequada relevância. De acordo com Cuba (2010), a Educação Ambiental bem planejada, permite a consciência socioambiental dos seus educandos e da comunidade escolar. Ssegundo Medeiros, Mendonça, Sousa e Oliveira (2011) a Educação Ambiental nos espaços escolares contribui para a formação de cidadãos conscientes, capazes de atuarem e tomarem decisões comprometidas com a realidade socioambiental de modo comprometido.

Para isso, é necessário que a Educação Ambiental esteja inserida no currículo escolar de forma continuada, inter e transdisciplinar. Alguns pesquisadores também defendem que ela deva ser tratada como uma disciplina (Cuba, 2010). 
Nesse contexto, é necessária uma Educação Ambiental crítica, a qual se propõe a desvelar a realidade, para inserir o processo educativo nela, contribuindo na transformação da sociedade atual (Guimarães, 2004). Ela contribui para efetivação de uma educação pautada na formação de um cidadão crítico e participativo diante das questões ambientais.

A fundamentação da Educação Ambiental, em conformidade com Gomes, Nakayama e Souza, (2016), vem a ser um dos pilares no processo de construção das sociedades sustentáveis e, nesse contexto, o educador é fundamental nesse processo educacional.

Portanto, na formação do pedagogo, a Educação Ambiental não deve ser tratada de forma secundária. Segundo Gomes et al. (2016), é necessário que o professor compreenda a complexidade da questão ambiental e suas implicações na vida cotidiana dos cidadãos.

Segundo Freire, Figueiredo e Guimarães, (2016), o pedagogo precisa refletir sobre sua prática pedagógica como educador ambiental crítico para que ela esteja transformando as condições sociais, visto que uma das incumbências da Educação Ambiental é a emancipação na busca da reflexão pela ação.

O objetivo desta pesquisa foi analisar e discutir a oferta da Educação Ambiental em cursos de pedagogia de Universidade federais do Brasil e as implicações para a formação do pedagogo em Educação Ambiental.

\section{Material e Métodos}

Esta é uma pesquisa de natureza quali e quantitativa. $\mathrm{O}$ critério para a escolha das universidades pesquisadas nesse estudo foi selecionar um curso de pedagogia presencial de universidade pública federal de cada capital do Brasil, totalizando 27 universidades e 27 cursos de graduação em pedagogia (Tabela 1).

Para a coleta de dados foi realizado um levantamento das grades curriculares dos cursos de pedagogia selecionados, nos sites das universidades. Esse levantamento foi feito no segundo semestre de 2017. Com isto, foi analisado por meio das ementas das disciplinas se ela buscava discutir questões acerca da Educação Ambiental. Visto que, se a pesquisa visasse apenas as disciplinas intituladas "Educação Ambiental" limitaria o resultado, foram consideradas as disciplinas que se relacionam ao meio ambiente e que traz com ela a temática da Educação Ambiental. Assim, buscou-se identificar as seguintes palavras-chave nas ementas: Educação e Meio ambiente; Educação, Sociedade e Ambiente; Educação Ambiental e Práticas Comunitárias; Fundamentos e Prática do Ensino de Ciências e Educação Ambiental.

Tabela 1. Universidades Federais pesquisadas por região.

\begin{tabular}{ll}
\hline \multicolumn{1}{c}{ Região Centro-Oeste } & \multicolumn{1}{c}{ Região Sudeste } \\
\hline Universidade de Brasília - UNB & Universidade Federal do Espírito Santo - UFES \\
Universidade Federal de Mato Grosso do Sul - UFMS & Universidade Federal do Rio de Janeiro - UFRJ \\
Universidade Federal de Goiás - UFG & Universidade Federal de São Paulo - UNIFESP \\
Universidade Federal de Mato Grosso - UFMT & Universidade Federal de Minas Gerais - UFMG \\
\hline \multicolumn{1}{c}{ Região Sul } & \multicolumn{1}{c}{ Região Nordeste } \\
\hline Universidade Federal do Rio Grande do Sul - UFRS & Universidade Federal do Piauí - UFPI \\
Universidade Federal do Paraná - UFPR & Universidade Federal de Alagoas - UFAL \\
Universidade Federal de Santa Catarina - UFSC & Universidade Federal da Bahia - UFBA \\
\hline \multicolumn{1}{c}{ Região Norte } & Universidade Federal do Ceará - UFCE \\
\hline Universidade Federal do Acre - UFAC & Universidade Federal do Maranhão - UFMA \\
Universidade Federal do Amazonas - UFAM & Universidade Federal da Paraíba - UFPB \\
Universidade Federal do Tocantins - UFT & Universidade Federal de Pernambuco - UFPE \\
Universidade Federal do Amapá - UNIFAP & Universidade Federal do Rio Grande do Norte - UFRN \\
Universidade Federal do Pará - UFPA & Universidade Federal de Sergipe - UFS \\
Universidade Federal de Rondônia - UNIR & \\
Universidade Federal de Roraima - UFRR & \\
\hline
\end{tabular}

Os dados foram tabulados em planilhas do software Microsoft Excel 2016 para análise descritiva dos dados e, utilizando o Software QGIS 2.18 foi possível a espacialização a frequência de ocorrência da oferta da disciplina, por região brasileira.

\section{Resultados e Discussão}

Dentre os 27 Currículos dos cursos de pedagogia das universidades públicas federais pesquisadas, $15 \%$ (4 cursos) ofertam as disciplinas de cunho ambiental como obrigatórias (Tabela 2), já os cursos que ofertam a disciplina de forma não obrigatória em seu currículo (eletiva/optativa) possui um maior percentual em comparação com a situação anterior, sendo 55\% (15 cursos) dentre os pesquisados, e 30\% (8 cursos) dos cursos pesquisados não ofertam a temática da Educação Ambiental inserida em seu currículo.

As disciplinas que discutem a temática de Educação Ambiental de fato não estavam priorizadas nos currículos dos cursos de pedagogia das universidades federais pesquisadas, sendo ofertada, principalmente, como conhecimento opcional (disciplina eletiva ou optativa).

As instituições de ensino superior que não ofertavam, no momento da pesquisa, em seus currículos disciplinas que discutam a temática de Educação Ambiental foram: Universidade Federal de Goiás (UFG); Universidade Federal de Mato Grosso (UFMT); Universidade Federal de Minas Gerais (UFMG); Universidade Federal do Paraná (UFPR); 
Universidade Federal do Rio Grande do Norte (UFRN); Universidade Federal de Roraima (UFRR); Universidade Federal de Santa Catarina (UFSC); Universidade Federal de Sergipe (UFS). Totalizando 8 cursos, o que representa $30 \%$ dos cursos pesquisados.

Outro fator agravante da atual situação da Educação Ambiental como disciplina no curso de pedagogia é a carga horária reduzida, dificultando que ocorra uma fundamentação teórica relevante capaz de desenvolver no educador habilidades que permitam uma leitura apropriada e aprofundada sobre a Educação Ambiental.

Tabela 2. Relação das Universidade federais pesquisadas que havia a Educação Ambiental citada nas ementas de suas disciplinas e sua carga horária.

\begin{tabular}{l} 
Disciplina obrigatório \\
\hline Universidade Federal do Acre (60h) \\
Universidade Federal do Amazonas (40h) \\
Universidade Federal do Piauí (60h) \\
Universidade Federal do Tocantins (60h) \\
\hline \multicolumn{1}{c}{ Disciplina Eletiva/Optativa } \\
\hline Universidade Federal de Alagoas (40h) \\
Universidade Federal do Amapá (60h) \\
Universidade Federal da Bahia (102h) \\
Universidade Federal de Brasília (60h) \\
Universidade Federal do Ceará (64h) \\
Universidade Federal do Espírito Santo (60h) \\
Universidade Federal do Maranhão (60h) \\
Universidade Federal do Mato Grosso do Sul (68h) \\
Universidade Federal da Paraíba (60h) \\
Universidade Federal do Pará (68h) \\
Universidade Federal de Pernambuco (45h) \\
Universidade Federal do Rio de Janeiro (45h) \\
Universidade Federal do Rio Grande do Sul (30h) \\
Universidade Federal de Rondônia (80h) \\
Universidade Federal de São Paulo (75h)
\end{tabular}

Observou-se que, $33 \%$ dos cursos de pedagogia das universidades pesquisadas na região $\mathrm{Sul}$ do país, apresentavam a Educação Ambiental inserida em alguma ementa de disciplina, o que correspondeu a $5 \%$ das universidades pesquisadas que tinham essa inserção. Dos 3 cursos pesquisados na região, apenas a Universidade Federal do Rio Grande do Sul (UFRS) possui a Educação Ambiental na ementa do curso ainda que de forma eletiva/optativa, e com carga horária de 30 horas. Para esses educadores se capacitarem minimamente no processo de Educação Ambiental, será necessário a busca de uma capacitação complementar.

A região nordeste possui o maior número de cursos pesquisados, devido principalmente ao número de estados. Dentre os 9 cursos analisados nessa região, 77,8\% (7 cursos) tinham a Educação Ambiental inserida em suas ementas, sendo que em seis cursos essa disciplina era eletiva/optativa. $\mathrm{O}$ maior percentual da presença da Educação Ambiental nos currículos é na região Norte, onde, dentre os 7 cursos pesquisados, $86,0 \%$ (6 cursos) possuíam a Educação Ambiental em suas ementas, sendo em três destes, de caráter obrigatório.
Nesse cenário, é preciso pensar e discutir acerca dos prejuízos que este silêncio pode vir causar na formação dos educadores, para que aconteça uma melhoria que incentive a inserção da Educação Ambiental de forma obrigatória nas grades curriculares dos cursos de pedagogia dessas instituições, para oportunizar qualificação adequada dos pedagogos atuarem, também, como educadores ambientais.

Segundo Lima, Carvalho, Araújo e Silva, (2016) o desempenho profissional do pedagogo requer seu constante processo aperfeiçoamento e qualificação, isso é preconizado nas Diretrizes Curriculares Nacionais de Educação Ambiental em seu Art. $9^{\circ}$ parágrafo único. É certo que é necessário que os educadores tenham essa capacitação de educador ambiental, para que possam dar suporte acerca desta temática sem cometerem o erro de caírem no senso comum e na superficialidade do assunto, a assim, passar a mediar sobre os diversos saberes ambientais com a profundeza e criticidade necessários.

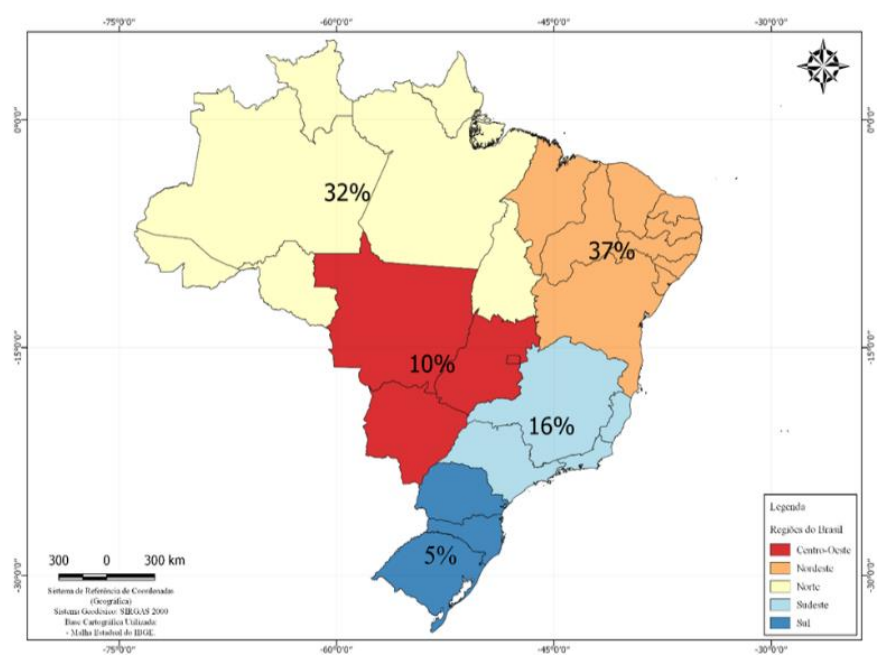

Figura 1. Distribuição, por região brasileira, do percentual de cursos de Pedagogia pesquisados que inserem a Educação Ambiental em suas ementas. Fonte: Elaborado para fins desse estudo. Vermelho (Centro-Oeste), Laranja (Nordeste), Amarelo (Norte), azul-celeste (Sudeste), Azul (Sul).

Sabendo da importância da discussão sobre a Educação Ambiental no processo formativo e de qualificação inicial de professores/educadores, Carvalho e Melo (2018) afirmam que com as problemáticas referente ao processo de ensinoaprendizagem da temática Educação Ambiental, é significativo o aperfeiçoamento teórico-prático na qualificação inicial e continuada do educador, para que ele possa fornecer subsídios para seus alunos tornarem-se indivíduos críticos e que busquem uma sociedade que entre suas preocupações preze pelo cuidado e respeito com o meio ambiente.

Segundo Pinto e Guimarães (2017) a destruição do meio ambiente e as crises ambientais, são reflexos da destruição vinda das grandes produções, desta forma, a Educação Ambiental tem papel primordial na construção de seres críticos, que compreendam que essa educação deve ser transformadora.

Segundo Carvalho e Melo (2018) a Educação Ambiental possibilita uma aprendizagem social e particular, dessa forma, 
a Educação Ambiental deve sensibilizar pessoas para mudanças de atitudes que gerem um ciclo de "boas ações" trazendo, consequentemente, benefícios para os seres vivos e a natureza.

Segundo Corrêa e Barbosa (2018), enquanto a Educação Ambiental estiver sendo aplicada nas escolas apenas como uma atividade de separação do lixo ou para ensinar a reduzir água e luz, sem os devidos fundamentos e as discussões sobre o papel do ser humano no cuidado da natureza, a consciência ambiental estará longe de ser obtida, atrapalhando o desenvolvimento de uma sociedade sustentável.

Segundo Arana e Bizzaro (2016) a Educação Ambiental é um mecanismo que proporciona as pessoas compreenderem de uma melhor forma os problemas ambientais, ocasionados pelo uso incoerente dos recursos naturais, possibilitando um conhecimento que permitirá uma transformação social. A Educação Ambiental é um meio de se levar o sujeito a ser crítico e se emancipar, que ele tenha a capacidade de discernir as ideologias que já estão muito firmadas em nossa sociedade. Segundo Rêgo, Araújo, Silva e Junior (2018), a Educação Ambiental como objeto transformador de uma sociedade reforça a educação como um processo diário e coletivo pelo qual os seres humanos agem e refletem, possibilitando a transformação da realidade.

É necessário começar a entender que os problemas ecológicos vivenciados não são algo natural e sim causado por condutas inadequadas e negligencias humanas. $\mathrm{O}$ texto Identidades da Educação Ambiental brasileira do Ministério do Meio Ambiente (2004), reafirma o pensamento de que, a Educação Ambiental não se refere exclusivamente às relações naturais e ecológicas, mas sim, a todas as relações que situam o homem no planeta e que se dão em sociedade.

Segundo Menezes, Nogueira, Paixão, Ponte e Pereira (2018) "devemos repensar as metodologias de ensinoaprendizagem no que tange a Educação Ambiental, pois percebe-se que algumas são menos eficazes que outras, cabendo ao docente rever suas formas de ensino com o intuito de contribuir para a formação integral dos discentes" (Menezes et al. 2018).

Em meio a tantas problemáticas das questões ambientais, os educadores ganham papel de destaque, pois é um dos profissionais mais importantes nesse processo educacional que visa a mudança de toda uma sociedade, então se deve estar atento a qualidade da formação desses profissionais, possibilitando todo um aparato para que eles possam desenvolver criticamente os debates e demais atividades voltadas à Educação Ambiental. Pinto e Guimarães (2017) afirmam que o professor deve construir uma prática que permita aos seus alunos serem críticos, a resistirem as problemáticas e buscarem soluções diferenciadas dentro do cotidiano escolar.

De acordo com Nóvoa (1992), a formação deve estimular uma perspectiva crítico-reflexiva, que forneça aos professores os meios de pensamento autônomo e que facilite as dinâmicas de auto formação participativa. Deve-se pensar numa formação crítica do educador que permita que ele tenha um posicionamento, pois, segundo Freire et al. (2016) "Criticar não implica, necessariamente, em encontrar defeitos e problemas, no aspecto negativo. Porém, atuar criticamente implica, sim, em uma postura atenta e problematizadora, não aceitando passivamente a realidade como dada" (Freire et al. 2016).

Conforme o observado, a identidade do educador ambiental não vem sendo construída na graduação e segundo a DCNEA (Diretrizes Curriculares Nacionais para a Educação Ambiental) em seu Art $9^{\circ}$, os cursos de formação inicial de professores devem disponibilizar conteúdos que discutam a ética socioambiental. De acordo com Dias et al. (2016) a educação é um processo que forma pessoas, com propósito de capacitá-las de maneira integral, entretanto a falta dessa educação voltada as questões ambientais trazem dificuldades para o educador quando ele precisa aborda a temática e até mesmo quando ele se interessa pelo assunto e quer ter sua formação especifica na área.

Segundo Nóvoa (1992), a mudança educacional depende dos professores e de sua capacitação, ou seja, é preciso uma sociedade que se preocupe com o meio ambiente, se querem seres críticos, que participem ativamente de debates sobre a temática ambiental, é necessário consentir ao docente uma qualificação que permitirá subsidiar discussões sobre a Educação Ambiental e, consequentemente, permitirá aos seus alunos, a comunidade e a todos envolvidos nos contextos escolar e do entorno da escola uma consciência socioambiental. Todavia, segundo Gomes et al. (2016) é necessário a compreensão do educador quanto a complexidade da questão ambiental e como ela traz consequências na vida das pessoas.

É fundamental que "o processo de construção da realidade socioambiental se concretize através do fazer pedagógico que se almeja para a Educação Ambiental" (Gomes et al. 2016). Portanto é de suma importância que o educador procure ter a competência necessária e dê subsídios para uma prática educativa crítica que permita aos alunos compreenderem a complexidade que a Educação Ambiental engloba. Entretanto, é necessário entender como transmitir tais assuntos. Segundo Monteiro e Monteiro (2017) os educadores refletem que a Educação Ambiental se constitui de uma prática contínua, buscando favorecer os estudos e atividades, que possibilitem a mudança de atitudes.

É preciso que o docente reflita sobre sua prática pedagógica enquanto educador ambiental para que ela esteja transformando as condições sociais e não apenas reproduzindo práticas predatórias, visto que "um dos papeis da Educação Ambiental é a emancipação (deixar de ser ator e ser autor); ou seja, "é a possibilidade de sair de mitos e padrões que foram construídos na história da modernidade". (Freire, 2016). Segundo Corrêa e Ashley (2018) "quando se discutir a implementação da Educação Ambiental nos currículos, projetos pedagógicos e em outros documentos acadêmicos, passa-se a sensação que os cursos de nível superior ainda não têm maturidade para dialogar a temática" (Corrêa \& Ashley, 2018).

A capacitação do educador não deve ser tratada de forma secundária quando está pautada na Educação Ambiental, pois só assim a Educação Ambiental conseguirá ter mais visibilidade, pois ela estará mais presente na comunidade, criando assim uma educação crítica que permitirá aos indivíduos compreenderem a destruição cotidiana da natureza 
e que possivelmente no futuro terá consequências.

Para que isto ocorra de forma efetiva o educador precisa estar qualificado, Carvalho e Melo (2018) afirmam que é indispensável o firmamento de políticas públicas voltadas para a docência, que possibilitem uma efetiva qualificação teóricoprática, de forma que venha a proporcionar ao educador domínio sobre a temática Educação Ambiental, para que assim seja possível uma qualificação adequada ao pedagogo, e ele possa fornecer subsídios aos seus alunos possibilitando que eles tenham uma Educação Ambiental crítica e ativa, para provocar mudanças na sociedade, pois permitindo que as pessoas conheçam, discutam e debatam está temática, se abrem precedentes a mudanças significativas no nosso meio ambiente.

\section{Conclusões}

Conforme a análise da pesquisa, em cerca de $30 \%$ dos cursos de pedagogia das universidades federais pesquisadas ainda não apresentam a Educação Ambiental evidentemente presente nas ementas das disciplinas. A região Norte apresentou a maior frequência de universidades que a insere, sobretudo de maneira obrigatória.

Dentre os cursos que já a incluem a Educação Ambiental nas ementas, muito poucas a incluem obrigatoriamente (disciplina obrigatória), tornando esse conhecimento opcional para o docente.

Com essa problemática na formação, sua atuação em sala de aula ficará comprometida, não favorecendo aos educandos uma destreza ambiental e crítica, que os torne sujeitos capazes de atuar de forma consciente numa sociedade que busca ser sustentável.

\section{Referências}

Arana, A.R.Z., \& Bizarro, L.M.C.T.. Educação Ambiental e Política Ambiental Integrada: o papel das univenidades. his Carpi Junior, salvador (org.); Leal. Antonio Cezar: Dias, lconicc Scolin. Educação Ambiental: conceitos, metodologias e práticas. tupit - sp: anap, 2016.

Carvalho, D., \& Melo, G. (2018). A educação ambiental na formação dos professores da EJA: elemento formativo do sujeito ecológico. Revista Eletrônica do Mestrado em Educação Ambiental, 35(1), 209-228. doi: https://doi.org/10.14295/remea.v35i1.7229

Corrêa, M., \& Ashley, P. (2018). Desenvolvimento Sustentável, Sustentabilidade, Educação Ambiental e Educação para o Desenvolvimento Sustentável: Reflexões para ensino de graduação. Revista Eletrônica do Mestrado em Educação Ambiental, 35(1), 92-111. doi: https://doi.org/10.14295/remea.v35i1.7417

Corrêa, T., \& Barbosa, N. (2018). Educação ambiental e consciência planetária: uma necessidade formativa. Revista Eletrônica do Mestrado em Educação Ambiental, 35(2), 125-136. doi: https://doi.org/10.14295/remea.v35i2.7692

Cuba M.A. (2010) Educação Ambiental nas Escolas. Revista ECCOM Educação, Cultura e Comunicação, 1(2), 23-31. Recuperado de http://fatea.br/seer/index.php/eccom/article/viewFile/403/259

Dias L.S., Leal A.C., \& Júnior S.C. (2016) Educação Ambiental: conceitos, metodologias e práticas. 1 ed. São Paulo, ed. Associação Amigos da Natureza da Alta Paulista. pp.187.

Freire L., Figueiredo J., \& Guimarães, M. (2016). O papel dos professores/educadores ambientais e seus espaços de formação, qual é a educação ambiental que nos emancipa? Pesquisa em Educação Ambiental, 11(2), 117-125. doi: http://dx.doi.org/10.18675/2177580X.vol11.n2.p117-125

Gomes R.K.S., Nakayama L., \& Souza, F.B.B. (2016). A educação Ambiental Formal como Princípio da Sustentabilidade na Práxis Educativa. Revista Eletrônica do Mestrado em Educação Ambiental, 33(2), 11-39.
Recuperado de https://periodicos.furg.br/remea/article/view/5280

Guimarães, M. A formação de educadores ambientais. Campinas: Papirus, 2004.

Lima, F., Carvalho, W., Araújo, C., \& Silva, J. (2018). Questões éticas na formação do pedagogo. Revista de educação do Vale do São Francisco, 7(14), 108-119. Recuperado de http://www.periodicos.univasf.edu.br/index.php/revasf/article/view/69

Medeiros A.B., Mendonça M.J.S.L., Sousa G.L., \& Oliveira I.P. (2011) A Importância da Educação Ambiental na Escola nas Séries Iniciais. Revista Faculdade Montes Beles, 4(1). Recuperado de http://www.terrabrasilis.org.br/ecotecadigital/pdf/a-importancia-daeducacao-ambiental-na-escola-nas-series-iniciais.pdf

Menezes J.B.F., Nogueira A.P., Paixão G.C., Ponte F.L., \& Pereira L.M.G. (2018). Conceitos, práticas de educação ambiental e formação cidadã na escola. Ambiente \& Educação, 23(1). Recuperado de https://periodicos.furg.br/ambeduc/article/view/6620/5299

Ministério do Meio Ambiente (MMA) (2004), Identidades da educação ambiental brasileira, Diretoria de Educação Ambiental, MMA, Brasília, Brasil. Recuperado de http://www.mma.gov.br/estruturas/educamb/_arquivos/livro_ieab.pdf

Ministério da Educação, 2012. Resolução N. ${ }^{\circ}$ 2, de 15 de junho de 2012. Diretrizes Curriculares Nacionais para a Educação Ambiental. Diário Oficial da União, Brasília, Brazil. N. ${ }^{\circ} 116$, seção 1, pp. 70. Recuperado de http://conferenciainfanto.mec.gov.br/images/conteudo/ivcnijma/diretrizes.pdf

Monteiro I.F.C., \& Monteiro A.D.E.B.S.C.O. (2017). A educação ambiental e as representações sociais dos professores da rede pública no ensino fundamental. Revista Brasileira de Educação Ambiental, 12(1), 165-176. Recuperado http://www.sbecotur.org.br/revbea/index.php/revbea/article/view/5092/3 240

Nóvoa A. (1992). Formação de Professores e Profissão docente. Lisboa, Portugal. Dom Quixote, pp. 13-33.

Pinto V.P.S., \& Guimarães M. (2017) A educação ambiental no contexto escolar: temas ambientais locais como temas geradores diante das questões socioambientais. Revista de Geografia, 7(2), 149-162. Recuperado https://geografia.ufjf.emnuvens.com.br/geografia/article/view/197

Rêgo J.R.S., Araújo M.G.S., Silva D.E.L., \& Junior F.M.C. (2018). O ambiente e suas problemáticas sob a perspectiva de profissionais da educação. Educação Ambiental em Ação, 65. Recuperado de http://www.revistaea.org/artigo.php?idartigo $=3425$

\section{Licença Creative Commons CC BY 4.0}

Este artigo foi publicado com acesso aberto para distribuíção sob os termos do Licença de Atribuição Creative Commons, que permite uso irrestrito, distribuição, e reprodução em qualquer meio, desde que o trabalho original seja devidamente citado. 